\title{
3266
}

\section{Fevipiprant reduces airway smooth muscle mass in asthmatics via PGD2 receptor antagonism}

Airway smooth muscle, Asthma - mechanism, Asthma management

R. Saunders $^{1^{*}}$, H. Kaul ${ }_{2}^{1}, \underset{1}{\text { R. Berair }}{ }^{1}$, A. Singapuri ${ }_{1}^{1}$, I. $_{1}$ Chernyavsky , L. Chachi , M. Biddle , A. Sutcliffe , M.

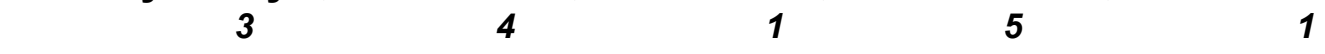
Laurencin , G. Bacher , M. Bourne , I. Pavord , A. Wardlaw , S. $1{ }^{3} \quad{ }^{6} \quad{ }^{2}{ }^{2}$

Siddiqui , R. Kay , B. Brook , R. Smallwood , C. Brightling

1

University of Leicester - Leicester (United Kingdom), University of Manchester - Manchester (United Kingdom), Novartis Pharma AG 4

Basel (Switzerland), Novartis Pharmaceuticals Corporation - East 5

Hanover, NJ (USA), University of Oxford - Oxford (United Kingdom), 6

University of Nottingham - Nottingham (United Kingdom), University of Sheffield - Sheffield (United Kingdom)

Introduction

Asthma is associated with increased airway smooth muscle (ASM) mass with increased disease severity and impaired lung function. The prostaglandin D2 (PGD2) receptor 2 (DP2) antagonist, fevipiprant, reduces airway eosinophilia and improves epithelial integrity, lung function, ACQ and $A Q L Q$.

Aim 
We investigated whether fevipiprant reduces ASM mass in asthma and potential mechanistic role of DP2 in airway remodelling using in vitro and computational modelling approaches.

\section{Methods}

ASM mass was assessed in bronchial biopsies from moderate-to-severe asthmatics in 12 weeks randomised placebo-controlled study of fevipiprant $225 \mathrm{mg}$ b.i.d. orally.

\section{Results}

ASM mass was significantly reduced following 12 weeks treatment with fevipiprant $(n=14)$ vs placebo $(n=13)$ (mean \pm SE change in $\%$ ASM area: $-13 \pm 5 \%$ vs $4 \pm 5 \% ; P=0.034$ ). Computational modelling predicted that reduction in eosinophilic inflammation and direct effect on ASM cell recruitment was required to explain reduction in ASM mass. ASM cells secreted more PGD2 following wounding (129 \pm 19 vs $181 \pm 25 \mathrm{pg} / \mathrm{mL} / 10$ cells; $P=0.020, \mathrm{n}=10$ ). Inhibition of DP2 activation by endogenous PGD2 resulted in reduced ASM migration (median [IQR] difference after 24h in presence of CAY10471 $100 \mathrm{nM}$ vs control, -11.0 [17.5] \%; $P=0.008$ ), but did not affect ASM proliferation over $72 \mathrm{~h}$.

\section{Conclusion}

Fevipiprant reduced ASM mass in moderate-to-severe asthma patients. This might reflect both reduced eosinophilic airway inflammation and a direct effect on ASM cells. 